\title{
Selection of Library Sites
}

By KEYES D. METCALF

$I^{\mathrm{s}}$ PROVIDING A NEW LIBRARY building for a college or university it might be supposed that the logical order of procedure would be to decide that it is needed, then to decide what sort of building it ought to be, and finally to decide where it should be placed. Unfortunately, however, the situation is practically never as simple as this. The availability or nonavailability of a satisfactory site is one of the factors that affect the decision on whether or not to build; this was the case at Harvard when replacement of the central library building was given up more than twenty years ago. ${ }^{1}$

One can hardly determine how much space is necessary for an adequate site unless one has studied the objectives of the library and projected its future growth. One can hardly judge whether or not a particular location will be reasonably convenient for those who use the library unless one can predict the extent and direction of future physical growth of the institution served by the library. If the institution is in its infancy and there is ample room, it may be wise to select the library site first and to plan the future building program for the whole college or university around it. More often, however, the problem is one of fitting a large building into an existing pattern that may have made no provision for it.

It should be emphasized also that one cannot design a satisfactory building and then look about for a parking space, if one is required, that is large enough and

1 The only available site for a new central library at Harvard was more than a quarter of a mile off center. This was not the only reason for the decision that was reached; tremendous costs were involved, and a building large enough to provide for another generation would have had to be so large that professors and graduate students, to say nothing of undergraduates, would have found it difficult to use.
Mr. Metcalf is Librarian Emeritus, Harvard College Library.

sufficiently convenient. Instead, many features of a good building are determined by its site. In order to compare the advantages of two sites, one must compare the two somewhat different buildings that could be erected on them.

The problems that have been outlined in the preceding paragraphs indicate that the selection of a library site is so important for an institution as a whole that it should be preceded in many instances, if not most, by the preparation of a master plan for physical development of the campus. This master plan should consider among other things the following:

1. The objectives of the institution.

2. The estimated prospective size of the student body and faculty, including separate figures for graduate and undergraduate students and professional schools, if there are any.

3. The size of the physical plant that will be required in the next generation and, if possible, for a longer period.

4. The parking facilities required for faculty, staff, and students.

5. The general landscaping plan for the campus.

6. Policy decisions in regard to the type and architectural style of the buildings to be erected.

Without a master plan for development of the institution's physical plant, the difficulties of selecting a satisfactory site for a new library will be greatly increased. It should be noted that there are architects and landscape architects 
who make a specialty of preparing master plans for the development of colleges and universities.

There are five major factors that should be taken into account in evaluating a site. First, is its size adequate? Second, what is its relation to neighboring buildings and to the whole population distribution and traffic flow of the institution? Third, what orientation is possible for a library building erected on it? Fourth, are there advantages or disadvantages in the slope of the land? Finally, what complications will arise from the nature of the ground beneath the building?

It may be, of course, that only one site will be available that is large enough and in an acceptable location. Even so, the other factors should be examined to determine how they will affect the proposed building. How, in other words, can it be designed to make the most of favorable circumstances and to overcome the difficulties presented by this site?

\section{Size of the Building}

A new building ought to provide for present collections, staff, and readers, plus anticipated growth for at least twenty-five years to come, and preferably for twice that period. There may be cases where for one reason or another it is impossible to build a new library large enough to be adequate for even twenty-five years. California planning authorities, because of the tremendous demands for additional space in the taxsupported institutions of higher learning in that state, have in certain instances ruled that new buildings constructed at this time should be large enough for five years only, after which a second stage of their construction should be proposed. In many rapidly growing state universities throughout the country the size of an addition to an old building or of the first stage of a new building is determined by the size of the appropriations that the university administration is able to obtain from the states' fiscal authorities, rather than by prospective needs during a specified number of years ahead. In private institutions also the sums that can be made available, rather than the needs, are too often the determining factor. Two points concerning future needs for space should be emphasized here.

1. If a new library or an addition to an old one is inadequate for space requirements for the next twenty-five years, disadvantages will result, and their cost should not be overlooked.

2. Serious as the disadvantages in 
question may be, an even more important consideration is selection of a site where a suitable and functional addition can be added at a later time. The site selected, wherever it is, should be large enough for additions that will extend the useful life of the building as long as it is adequate functionally.

Even when a minimum square footage has been determined for a building and its prospective additions, there is, alas, no formula that will translate this into the minimum dimensions for the site. A building does not look good if it fills a plot too full. Spacing of buildings is an aesthetic problem and is affected by what has been done already on a campus or is planned for the future. Proper landscaping can often help to make space go farther than has been expected, and its possible usefulness in this connection should not be neglected.

It may not be out of place here to remind librarians, administrative officers of educational institutions, and even, in a few cases, architects, that a college or a university that prides itself in providing its students with a good liberal education should appreciate the fact that a handsome, comfortable, and functional library building may have an important contribution to make in bringing about the desired results of the whole educational process. A library should not be a monument. It should not be wasteful of space. It should be economical in construction, always taking the long view and considering the cost of maintenance, as well as the original building costs; but it should provide also an atmosphere that encourages and helps to make possible good hard work on the part of students and faculty.

The size of the plot that is needed also depends on the height of the building, which involves functional as well as aesthetic considerations. The number of floors that will be satisfactory from the functional standpoint cannot be determined without taking account of the total square footage, the type of library, its collections, and use.

A library requiring ten thousand square feet or less, and often considerably more, will usually be more satisfactory if it is all on one floor. In larger libraries, it is often desirable that the entrance level and the one above, plus the one below, particularly if it has windows, be large enough to house the central services ${ }^{2}$ and provide seating for at least 75 per cent of the readers-particularly those who come and go at short intervals. If this is practicable, there will usually be no serious problems with public elevators. The most heavily used books ought to be shelved comparatively close to the entrance. Other things being equal, the majority of readers should not have to travel any longer distances than necessary, either horizontally or vertically, within the building.

Sometimes a site will prove to be large enough for a building and its additions only if expansion takes the form of additional floors. This is expensive and inconvenient, but, even so, may be preferable to any alternative. At the Louisiana State University, for example, the library has a central location in the heart of the campus and fills the available plot almost completely. This was realized and accepted when the building was planned; the architect provided for construction that will make it possible to add two more floors when they are needed.

The total height of a building above ground is determined by four factors: the percentage of the building that is below ground level, the number of stories above ground level, the height of these stories,

2 The central services referred to here are generally considered to include the circulation and reference desks, with the offices and service areas that go with them, the bibliography and reference collections, with such reading space as they require, the public catalog and in many cases the current periodical collections, with an attached reading area, and also accommodations for the use and storage of microreproductions if it is desired to service them from one of the service desks mentioned above. To this should be added at least the work areas housing those members of the processing staff (particularly acquisition and catalog) who have frequent need for using the catalog and the reference and bibliography collections. 
and the thickness of the floors between finished ceilings and finished floors above. If a large part of a building can go below the entrance level, as at the Princeton University library, which in some ways resembles an iceberg with the major fraction of its square footage in its three basement floors, the total height will be correspondingly reduced. It should be noted that the percentage of space required for stairs and elevators increases with each story that is added. Also, three stories with eight-foot ceiling heights require no more height than two stories with twelve-foot ceilings, except for the thickness of one additional floor. In buildings with as many as five stories above ground the thickness of floors is an important factor in its total height; if each one, for instance, is five feet thick instead of two, the five would take $5 \times 5$, or $25 \mathrm{feet}$, instead of $5 \times 2$, or 10 feet, making a difference of 15 feet, or enough space to provide two additional stack levels. Thick floors make it easy to plan ducts and services that can be run almost anywhere, but it is more economical of space and gross cubature to run services vertically in so far as possible, rather than horizontally.

\section{Central or Eccentric?}

The library has often been called the heart of the university; it is visited frequently by nearly everyone in the institution and, if a good library, will be used at least as much as any other building on the campus. Obviously, its location ought to be convenient. Does this mean near the dormitories, the classroom buildings, the laboratories. the student union, or the athletic field?

No one answer is correct for all institutions. If most students commute to the campus, it may be best to place the library near the transportation center, enabling the student to return books on his way to classes and borrow others as he is leaving. The location of lockers for com- muting students may also be an important consideration.

A location near the classroom center is usually preferable to one near the dormitory center; to lengthen the walk to the library between classes by two minutes is more disadvantageous than to lengthen by five minutes the time required to reach the library in the evenings from dormitories. ${ }^{3}$ If there are dormitories on opposite sides of the campus, as in many coeducational institutions, a location near classroom buildings may be approximately equidistant from the dormitories. If a choice must be made, it is preferable to place the library near classrooms for the humanities and social sciences, rather than near those for the sciences. If it is much easier, either in the daytime or evening, to reach the student center than the library, a temptation to defer study has been left in the student's path.

Convenience evidently implies a central location, but it is possible for a site to be too central. Some campuses still have a large unoccupied space in their central squares, and this might at first glance seem to be an ideal site for a new library. In fact, however, there are usually serious drawbacks.

First, because the space is so centrally located and conspicuous, the donor, and less frequently, the officers of the college and even the architect may be tempted to decide that it is the place for the single monumental building on the campus. To be sure, it is possible for a good library to be a monument, but it is less likely to be a good functional library if it is planned primarily as a monument. The successful combination is rare. Moreover, a monumental building usually costs much more than one that is simply functional. If funds available for library construction are limited, it may be impossible to pay for the space that is needed if

3 Some librarians disagree with this argument, on the basis that evening study is on the whole more important and that the library should be as close to the dormiaries as possible. 

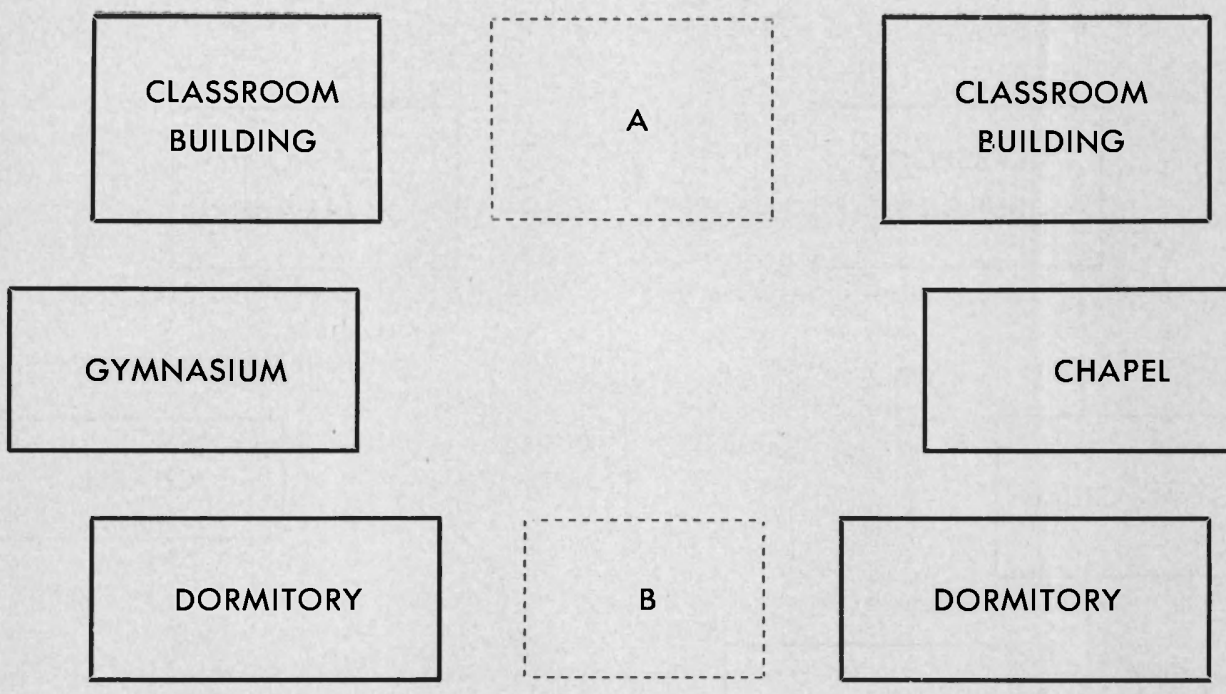

A-Suitable site for library, near classroom buildings.

B-Possible site for library, but one closer to classrooms is to be preferred.

this space has to be housed in a building that is to be the showpiece of the campus.

Second, if a library is in the center of the campus, with students approaching it from all directions, there will inevitably be demands for public entrances on all sides. One objection is that each entrance, with the lobby attached to it and the corridors leading from it to the circulation desk and other central services, takes valuable space. If, for example, an extra entrance requires an outside lobby of only 100 square feet, plus a small inside lobby of 500 square feet, plus a corridor (otherwise unnecessary) 100 feet long and 10 feet wide, there is a total of 1,600 square feet that adds nothing to the building's seating or shelf capacity, which may also interfere, sometimes seriously, with its functional properties, and costs perhaps $\$ 20,000$. This is only 4 per cent of the total in a $\$ 500,000$ building, but it would provide space for shelving 25,000 volumes or, used as endowment, would bring in an income of $\$ 1,000$ per year for books or services.

The extra entrance will prove to be still more expensive if the library decides, as more and more libraries have done, that the cheapest and most effective way to supervise the building is not to have an attendant in each reading area, but to check all readers at the exits as a means of discouraging unauthorized borrowing. If this is done in a building open eighty hours per week, a very modest number of hours today when student and faculty pressure is for a midnight or later closing time, each exit may increase the payroll by $\$ 4,000$ to $\$ 6,000$ annually. It will be hard to resist the demand for additional entrances and exits if the building is too centrally located; students and professors do not like to walk around a building and then have to return part of the way as soon as they enter.

The third, and, in many ways, the most serious objection of all to a location at the exact center of things is that it increases the difficulties of making an addition to the building that will be aesthetically and functionally satisfactory. Often, indeed, it makes an appropriate addition difficult if not impossible. A central building tends to be 

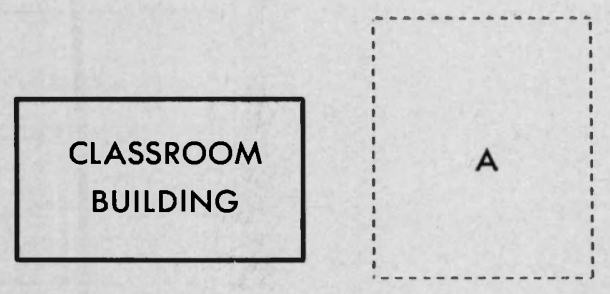

\section{CLASSROOM \\ BUILDING}
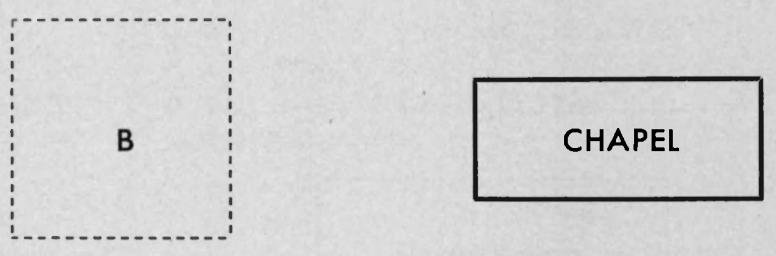

\section{GYMNASIUM}

\section{CLASSROOM} BUILDING

If $\mathrm{A}, \mathrm{B}$, and $\mathrm{C}$ are proposed sites for the library, it may be observed that-

$A$ is too small a space, and an addition would be difficult, if not impossible.

B would also be hard to expand, and would call for entrances on all sides; its central location would increase the temptation to erect a monumental structure.

C appears to be the most desirable location for the library.

symmetrical, and an addition usually threatens to destroy this symmetry. If it is also monumental, the cost of an addition will be greatly increased. Perhaps it should be emphasized once more that most library buildings, if they continue to serve the purpose for which they were designed, have to be enlarged sooner or later, and ought to be planned with this in mind.

What is wanted, then, is a convenient location, but not one so central that it calls for an unreasonably expensive, monumental, and unfunctional structure. The accompanying drawings illustrate some of the points that have been made.

\section{ORIENTATION}

No single orientation is ideal for all seasons, climates. and other conditions; but orientation is a factor to be considered, particularly in areas where extremes of heat or cold, hard winds, or intense sunlight may be expected. Near the tropics the sun shines in east and west more than in south windows. As one goes farther north, the southern sun becomes more and more of a problem; the situation is reversed, of course, south of the equator.

The extent to which sunlight penetrates into rooms at the hottest time of day is a matter of some importance in most areas. The problem is minimized if it is usually cloudy, and, in a country where central heating is not customary, the winter sun may be a useful source of heat. More commonly, however, when direct sunlight streams into a building it creates glare and overheating; if there is air conditioning, it adds to costs. An 
architect should be able to provide drawings showing the penetration of sunlight into a room at any latitude during any month of the year for any proposed orientation of a building.

The amount of direct sunlight, as well as heat and cold, that enters a room depends also, of course, on the height of windows, the percentage of wall space that they occupy, and the depth of the rcom from windows to inner walls. Prevailing winds and extremes of heat and cold should also be taken into account; double windows and certain special kinds of glass may do much to counteract unfavorable conditions, but they are expensive and sometimes difficult to replace. Outside screens have been developed in recent years to reduce the problems resulting from excess sunlight.

In most parts of the United States the western sunlight is the most difficult to control. The eastern sunlight generally presents much less of a problem because it is rarely as hot and the sun is ordinarily higher above the horizon and so penetrates a room a shorter distance by the time the library is open or is heavily used. The southern sunlight becomes more of a problem as distance north from the equator increases. Sunlight rarely causes trouble in northern windows of this hemisphere, as it occurs only in early mornings and late afternoons when the sun is not at its brightest, and can usually be kept out during the summer months by relatively inexpensive landscaping.

The use of special glass and screens of one kind or another some distance beyond the outside walls has already been mentioned as a means of protection from glare and heat. In addition, there are awnings, louvres projecting horizontally from the building above windows, and metal, vertical venetian blinds outside the building. The screens may be of metal, hollow tile, or wood. They may be placed a few feet beyond the outside wall and can protect windows from di- rect sunlight except, possibly, for a few minutes at the end of the day on a western exposure. Examples of such screens can be found in the undergraduate library of the University of South Carolina, the new University of South Florida in Tampa, and the New Orleans Public Library, to mention only a few. Inside the windows, venetian blinds (vertical or horizontal), curtains, or drapes will help, but these sometimes tend to interfere with the circulation of air in an unexpected fashion, and may add to the air conditioning load in summer and heating in winter. All cost something and often a good deal. An engineer should be asked to supply estimates for the specific locality.

It should not be forgotten that a reduction in the percentage of glass in the walls will reduce considerably the heat and cold that is transmitted to the inside. Some architects prefer all-glass buildings, which can be very effective aesthetically. Others prefer to have no windows at all, or very few, with a wall pattern to provide the architectural effects desired. Though small window areas produce savings on heating and air conditioning, they may necessitate lighting over a longer period, but the additional resulting cost is rarely great. A library open for fourteen hours a day in a climate with an average amount of sunlight will require artificial lighting for reading approximately half the time it is open, even if it has large windows, and, while many readers feel the need of windows or tend to have claustrophobia without them, it should be remembered that the light that comes from windows is not for reading but for readers.

It has been said that the western sunlight is the most objectionable throughout most of the United States. It follows that a rectangular building with long north and south sides and short east and west walls is to be preferred if practicable in other respects. If the long axis 
runs directly east and west, objectionable effects of sunlight will be minimized. If a building faces to the southwest or southeast, it will usually suffer from both the southern and western sunlight even more than if it faces straight south. In addition, the eastern sunlight will be more troublesome, and, in late afternoons, it will come in on the northwest side. In other words, a building that is placed at a forty-five degree angle from north to south tends to have much greater difficulty from excess sunlight than one that has its main axis either straight north and south or east and west.

If the north side of a building is the best area for reading, it will be preferable, other things being equal, to have the main entrance on the south, leaving the entire north side free for reading space. Furthermore, if the stronger winds and storms usually come from the north and west, an entrance on the south or east is preferable and may require a smaller entrance lobby than would otherwise be needed.

It should be kept in mind that direct sunlight, with its ultra-violet rays, is harmful to book bindings and paper. Book ranges should not extend to a wall where the sunlight can come through windows between them; if ranges extend to any wall, they should do so only on the north. The ranges should be at right angles to walls that have windows; if they parallel such walls the full force of the sunlight will strike the volumes in the first range with full force.

It is obvious that the ideal for most of the United States-a library with its entrance on the south and its long axis running directly east and west-is impractical in many cases because of other considerations. A convenient location is more important than an ideal orientation; but orientation is a factor to be considered, and its effect on building costs should not be overlooked. If other factors dictate a particularly undesirable orientation, special attention should be given to avoiding the complications that would arise from large areas of unprotected glass.

\section{The Slope of The LAND}

If a campus is flat, as many are, one site is like another as far as slope is concerned. In other cases, however, the extent to which the ground slopes and the direction of the incline may be important considerations.

A flat site is not ideal; it has distinct disadvantages. If the main entrance is to be at ground level or only one step up, it will probably be difficult, if not impossible, to have windows in the basement. This may not be of too great importance, but it is true that, even with the best of air conditioning and lighting, some persons are inclined to think that reading and staff accommodations without any outside light are substandard. This is particularly likely to be true if the rooms also have low ceilings, as they often do in basements. A basement is not essential, and may be impractical because of ground and soil conditions; but a basement can provide a large amount of space comparatively inexpensively. Indeed, with central heating and air-conditioning plants for whole campuses, basement space is often not needed for machinery, and there may be as many square feet to be assigned to readers or books in the basement as on any other floor-more, usually, than on the main floor, where a large entrance lobby is almost always needed. If the basement has windows, this space may be highly attractive, and it has the great advantage of being only a short flight of steps from the entrance level. It may also make possible a separate entrance and, if so, can house facilities that are open at times when the rest of the building is closed.

It should be noted that a short flight of steps leading to the entrance on the main floor may make it possible to have a basement with windows all around, 
but it should be remembered that a building without such steps, entered directly from the grade level, is likely to be more inviting. Areaway windows can sometimes provide nearly as much light as those above ground, but they entail problems of landscaping and drainage. If the first floor is approximately thirty inches above ground level on a flat site, a loading platform at the rear is automatically available; this is not essential, but it is a convenience, even now when most shipments reach a library in small parcels rather than in the tremendous packing cases that used to prevail. Shipments leave the library also, it should be remembered.

One further observation on flat sites may be made. If soil conditions permit, modern earth-moving machinery can change ground levels a few feet at small expense, and, with adequate landscaping, the results may be excellent. It may thus be possible to have a front entrance at ground level, but with a loading platform at the rear.

A considerable slope may be a distinct advantage or disadvantage, depending on its location. In a given site, there is usually one side where it is obvious that the main entrance ought to be-a point at which traffic to the library naturally converges. If there is a fairly steep downward slope from this entrance to the back of the building, it should be possible to have windows in the basementpossibly on as many as three sides and even part of the fourth. Indeed, if the slope is sharp enough, there may also be windows in a subbasement or, as it is sometimes called, the "minus-2" level. At Princeton, even the "minus-3" level has windows at the rear. A slope of this kind offers the further advantage of reducing the height of the building above the entrance level. One may enter a fivestory building at the middle of its five levels; this may make it possible to dispense with a public elevator if there is a service elevator for the transfer of books and for persons who cannot climb stairs.

In order to avail themselves of a basement or "minus-1" level, some libraries have an entrance set back from the top of a hill and reached by a bridge, as at the Carleton College library in Northfield, Minn. Construction of a short ramp up to the front entrance can serve the same purpose. At the Grinnell College library there is a ramp and then a bridge to the entrance; the result is that, though the campus is relatively flat, windows could be provided wherever wanted in the basement.

On the other hand, if there is a sharp upward slope toward the rear of a building, the back of the first floor may have to be sunk into the ground; windows may not be possible on one or more sides of the first floor and there will be none at all in the basement. This may be a disadvantage if natural lighting is desired, and may also involve difficult drainage problems.

If the ground falls off to one side of an entrance and rises on the other side, it may facilitate basement fenestration on one side but make it impossible to provide windows on the other side of the main floor. It will probably complicate the landscaping and make architectural planning of the building more difficult. It may also seriously complicate plans for a subsequent addition.

In general, then, a site is to be avoided if the ground slopes upward from the entrance or if it slopes from one side of the entrance to the other. A flat site is to be preferred to one that slopes objectionably; but it is better yet if the ground slopes from the entrance downward toward the back of the building. No one of these factors is of first importance. But, other things being equal, they may prove to be the deciding considerations on site selection.

\section{Soil and Ground Conditions}

A site for a library should never be 
selected without some knowledge of ground conditions. When general information on this subject is not available, at least one or two and in many cases a larger number of preliminary borings should be made. This may seem expensive, but it will cost hundreds rather than thousands of dollars at most, and will be well worth the cost if it prevents great unanticipated expenses for excavation and foundations-misfortunes that have been much too common in library building. One university library had spent more than $\$ 60,000$ on its plans before it realized that foundations alone for its library would cost approximately $\$ 500,000$ extra because of ground conditions.

This is not an engineering treatise, and it should suffice to give a brief summary of the points that ought to be considered.

If the foundation runs into ledge or boulders over one-half cubic yard in size, there may be substantial additional costs for removing this material. The extra costs which would result from placing a building in this type of soil should be carefully estimated by a qualified professional estimator or a contractor familiar with this kind of work. On the other hand, it should be kept in mind that solid rock makes a fine foundation for a library; books are heavy, and stack areas in particular need a firm foundation. In excavating for the Lamont Library at Harvard shale was reached before the foundation was excavated to the proper depth, but practically all of it was friable enough to be handled by a power shovel, and, as it was removed, an excellent foundation of harder rock was exposed for the footings.

If loose, fine sand, soft clay, silt, or peaty materials are encountered, piles or caissons may have to be driven down great distances in order to provide an adequate foundation. Along the Charles River in Cambridge and in the Back Bay section of Boston (areas that once were tidal swamps) it may be necessary to go two hundred feet or more below the surface to reach a solid bottom, and the cost of driving piles or sinking caissons to this depth is great. Under certain conditions it is possible to pour a concrete mat on which the building will "float." The library of the Massachusetts Institute of Technology is floated in this way, but adoption of this method dictated the construction of the building around a large court in order to spread the weight, and this resulted in a disadvantageous circulation pattern. The Yale University library is built over quicksand on which a concrete slab was poured, but conditions were such that it was possible to build a tower stack, despite the great weight of such a structure.

In many sections of the country there are numerous springs, sub-surface ground water flow, or other water conditions to complicate the construction of foundations. It is possible to excavate for a foundation, keep the water pumped out, and waterproof the building either outside or in; but this is expensive and, unless the construction is of highest quality, difficulties will arise sooner or later. During flash floods, the water table around the Widener Library at Harvard occasionally rises above the sub-basement floor; on two occasions during nearly fifty years water has come up through the concrete slab in small sections of the floor.

Another problem sometimes occurs on hillsides, which have been particularly recommended, if they slope the right way, as building sites. In certain ground formations, however, the whole side of the hill may begin to slide in wet weather, as has happened occasionally in canyons of the Los Angeles region.

The Louisiana State University library at Baton Rouge is built on Mississippi River delta land that can carry only a limited weight per square foot of surface. It was necessary to reduce the pressure on (continued on page 222) 
EugEne F. Gilroy, librarian of St. Joseph's College, Philadelphia, Pa., died suddenly on December 23, 1960.

Vladimir Gsovski, chief of the European law division in the law library, Library of Congress, died January 12 at the age of sixtynine.
Philip Krichbaum, a staff member of the subject cataloging division, Library of Congress for nearly twenty years, died January 14.

JEROME VALENTINE, senior research analyst in the air research division, Library of Congress, died January 18.

\section{Selection of Library Sites}

(continued from page 192)

the bearing strata by removing the overburden. This made it necessary to include a basement in the building, and this involved a drainage problem. The basement and the drainage difficulties could have been avoided if the site had not been so small that it was necessary to plan for a five-story building.

\section{SUMMARY}

A specific example illustrating some of the considerations involved in the selection of a site may be provided by the Lamont Library at Harvard. This site was selected from four possibilities after some weeks of discussion and preparation of rough sketches of a suitable building in each location. Its actual position was chosen because:

1. It was the only remaining available site in the Yard large enough for a building of the desired size. A location in the Yard close to the two other central library buildings, Widener and Houghton, to which it could be connected by tunnel, was an important factor.

2. It was so placed that the freshmen had to pass its front entrance six times a day going to and from their meals in the Freshmen Union. It was on a main walk between the houses where the upper classmen lived and the classrooms, and closer to the latter.

3. It had a long east-west axis, giving the most desirable long north and south exposures for the reading areas.

4. The ground slope was such that two levels with windows below the main entrance, which was only one short step up, were possible, with two more without windows below them. It was possible to have the entrance level, plus its mezzanine, a full second floor, and a penthouse with a good deal of useful space in it; even the latter is closer to the ground than the main reading room in Widener. Moreover, the building, which would have been a little large for its site if it had been taller, does not give that impression.

5. Policy decisions on the part of the university permanently limiting the size of the undergraduate college and on the part of the library limiting the size of the undergraduate book collection meant that provision did not have to be made for a future extension.

To recapitulate, the site must be large enough to provide for the building and for projected additions, and it must be in as convenient a location as possible. This does not mean that it ought to be in the exact center of the campus; but it ought to be readily accessible from classroom buildings, particularly those for the humanities and social sciences. The orientation, ideally, should be on a long axis running directly east and west, with the entrance on the south. A site that slopes downward from the entrance to the rear may be advantageous, and costs of construction may be greatly increased if ground conditions are unsatisfactory. Parking and delivery problems should not be forgotten. Since a site will rarely be found that is ideal in every respect, careful assessment of the advantages and disadvantages of each possible site is called for before a decision is made. 